\title{
Efeito do congelamento sobre a viabilidade de células leveduriformes
}

\author{
Effects of freezing on the viability of yeasts cells
}

\author{
Andréia Spanamberg', Edna Maria Cavallini Sanches', Jennifer Hummel' \& Patrícia Valente²
}

\begin{abstract}
RESUMO
O controle de produtos de origem animal está diretamente associado à sanidade animal e à saúde pública. Na suspeita de mastite, tanto bacteriana quanto micótica, o congelamento de amostras de leite permite aumentar o período de tempo para análise microbiológica, permitindo um correto diagnóstico laboratorial. As leveduras são os principais agentes ambientais envolvidos na mastite micótica. O objetivo do presente trabalho foi verificar se o congelamento afeta a recuperação de leveduras potencialmente presentes no leite. Foram utilizados seis isolados: Rhodotorula sp. (L1), Geotrichum sp. (L2), Cryptococcus sp. (L3), Candida tropicalis (L4) e Candida albicans (L5), oriundos de leite in natura, e um isolado de C. parapsilosis (ATCC 22019). Após a inoculação experimental, as amostras foram congeladas durante 10 dias, 3 , 6 e 8 semanas. O congelamento do leite por períodos superiores a 10 dias causou redução no número de células viáveis. Sugerimos que sejam utilizados períodos mais curtos de congelamento para a análise micológica do leite.
\end{abstract}

Descritores: mastite micótica, leite congelado, viabilidade celular, leveduras.

\section{ABSTRACT}

The control of animal products is directly linked to the animal sanity and public health. When suspecting mastitis, either bacterial or mycotic, freezing milk samples increases the period of time for a microbiological analysis, thus allowing a correct laboratorial diagnosis. Yeasts are the main environmental agents involved in mycotic mastitis. The objective of the present work was to verify if freezing affects the recovery of yeasts present in the milk. Six isolates were used: Rhodotorula sp. (L1), Geotrichum sp. (L2), Cryptococcus sp. (L3), Candida tropicalis (L4) and Candida albicans (L5), isolated from milk in natura, and one C. parapsilosis (ATCC 22019) isolate. After experimental inoculation, the samples were frozen during 10 days, 3, 6 and 8 weeks. Milk freezing for periods longer than 10 days caused a reduction in the number of viable cells. We suggest that shorter freezing periods are used for the mycological analysis of milk.

Key words: mycotic mastitis, frozen milk, cellular viability, yeasts. 


\section{INTRODUÇÃO}

Mastite é uma doença que acarreta enormes prejuízos à pecuária leiteira, tanto na quantidade quanto na qualidade do leite produzido, com conseqüências na produção dos derivados lácteos. Cada vez mais, a literatura registra casos esporádicos de microrganismos de origem ambiental, sendo as leveduras os principais agentes ambientais envolvidos $[6,10]$. A mastite fúngica ocorre sob a forma de surtos localizados [3,5] e/ou após tratamento com antimicrobianos [8]. As principais leveduras envolvidas na mastite pertencem aos gêneros Candida e Cryptococcus, seguidos por outros gêneros como Geotrichum, Pichia e Trichosporon [2,11-13].

$\mathrm{O}$ controle microbiológico do leite é fundamental para uma correta identificação dos microrganismos causadores de mastite. Uma prática utilizada é o congelamento de amostras de leite oriundas de animais com suspeita de mastite, porém, poucos trabalhos indicam o tempo adequado em que as amostras podem permanecer congeladas. O objetivo deste estudo foi, portanto, avaliar a influência do congelamento do leite sobre a viabilidade de células de leveduras associadas à mastite micótica.

\section{MATERIAIS E MÉTODOS}

Foram utilizados no estudo seis isolados: Rhodotorula sp.(L1), Geotrichum sp. (L2), Cryptococcus sp. (L3), Candida tropicalis (L4) e Candida albicans (L5), oriundos de leite in natura, e um isolado de $C$. parapsilosis (ATCC 22019). Cada isolado foi inicialmente cultivado em meio ágar Sabouraud ( $2 \%$ glicose, $2 \%$ ágar, $1 \%$ peptona, $0,05 \%$ cloranfenicol) por 3 a 5 dias a $25-30^{\circ} \mathrm{C}$, e diluído em água destilada estéril $(2 \mathrm{~mL})$, até atingir uma turvação grau 2 da escala de Wickerham [18]. Após, uma alíquota de $200 \mathrm{~mL}$ foi assepticamente inoculada em tubos de ensaio contendo $10 \mathrm{~mL}$ de leite UHT, totalizando cinco amostras de cada isolado. Cada amostra, após a homogeneização, foi congelada em freezer comum durante quatro períodos distintos (10 dias, 3, 6 e 8 semanas). Uma contagem controle da amostra foi realizada no início do experimento. Para realização da contagem de células viáveis, as amostras foram descongeladas, submetidas a diluições decimais seriadas e semeadas em triplicata através da Técnica de Espalhamento em Superfície em meio YM ( $1 \%$ glicose, $0,3 \%$ extrato malte, $0,3 \%$ extrato de levedura, $0,5 \%$ peptona, $2 \%$ agar, $0,05 \%$ cloranfenicol, $\mathrm{pH} 4,5$ ), sendo as placas de petri incubadas a $25-30^{\circ} \mathrm{C}$ durante 3-5 dias.
Os dados foram analisados através do teste de Comparações Múltiplas de Dunnet para dados ponderados (nível de significância 5\%) para a avaliação das médias de contagens durante o período de congelamento para cada amostra.

\section{RESULTADOS}

Todos os isolados testados foram recuperados após o congelamento das amostras durante 10 dias, 3,6 e 8 semanas, embora a viabilidade celular tenha diminuído (Tabela 1). À exceção de uma amostra (Candida parapsilosis - ATCC 22019) com 10 dias de congelamento, todas as demais apresentaram diferença significativa nas contagens.

Tabela 1. Resultado da viabilidade de células leveduriformes (log.UFC.mL) após o congelamento das amostras em diferentes períodos.

\begin{tabular}{|l|c|c|c|c|c|}
\hline \multicolumn{1}{|c|}{ Isolado } & Dia zero & 10 dias & 3 semanas & 6 semanas & 8 semanas \\
\hline Rhodotorula sp. (L1) & 5,76 & 4,50 & 4,11 & 3,43 & 3,35 \\
\hline Geotrichum sp. (L2) & 5,64 & 5,31 & 5,25 & 4,13 & 3,66 \\
\hline Cryptococcus sp. (L3) & 5,59 & 4,69 & 4,43 & 4,07 & 4,37 \\
\hline Candida tropicalis (L4) & 5,98 & 5,77 & 5,75 & 5,15 & 5,07 \\
\hline Candida albicans (L5) & 5,64 & 5,04 & 4,58 & 4,38 & 3,88 \\
\hline $\begin{array}{l}\text { Candida parapsilosis } \\
\text { (ATCC 22019) }\end{array}$ & 5,43 & $5,02^{\mathrm{a}}$ & 4,38 & 4,38 & 3,99 \\
\hline
\end{tabular}

${ }^{a}$ resultado com diferença não estatisticamente significativa em relação ao dia zero.

\section{DISCUSSÃO}

A utilização de leite congelado para exame microbiológico pode ser uma prática adequada para um correto diagnóstico do agente etiológico envolvido, visto que o congelamento do leite permite aumentar o prazo para a realização do teste, possibilitando a estabilidade dos organismos presentes [1]. Segundo Gomes et al. [9], o congelamento do leite não altera suas características químicas e microbiológicas, embora alguns microrganismos possam não suportar o processo [15]. Estudos realizados com leite proveniente de animais com mastite clínica e subclínica relataram que o congelamento das amostras por 4 a 16 semanas não afetou a viabilidade de todos os patógenos bacterianos envolvidos na enfermidade [4,16]. Costa et al. [7], em 256 amostras procedentes de animais com mastite clínica, não observaram 
diferenças no diagnóstico microbiológico do leite "in natura" e pós-congelamento. A contagem das leveduras em nosso experimento foi significativamente inferior à inicial até o final do teste, resultado semelhante ao encontrado em amostras de queijo produzidos com leite de ovelha e em suco de fruta congelado $[14,19]$. A redução na contagem pode ser explicada pela provável lesão provocada nas células devido à formação de cristais de gelo durante o congelamento [17].

\section{CONCLUSÕES}

O estudo demonstra que os isolados inoculados experimentalmente puderam ser recuperados após o período de congelamento, apesar de ter havido redução da viabilidade celular mesmo após curtos períodos de congelamento. Isso sugere que a utilização de amostras de leite congeladas por períodos inferiores a 10 dias é mais adequada para o diagnóstico de mastite micótica através do exame microbiológico, propiciando adequado diagnóstico e conduta terapêutica.

\section{REFERÊNCIAS}

1 Alcarde A.R. \& Basso L.C. 1997. Efeito da trealose na manutenção da viabilidade de células de leveduras desidratadas por liofilização. Scientia Agricola. 54: 3.

2 Alvarez H. \& Flores C. 1962. Micologia em leche de vacas sanas y com mastitis. Sociedad de Medicina Veterinaria de Chile.12: 11-17.

3 Benesi F.J., Birgel E.H., Gandra C.R.P., Araújo W.P. \& Fanucchi M.V.S. 1983. Mastite bovina causada por levedura Candida rugosa. In: Anais da $2^{a}$. Semana de Veterinária da Faculdade de medicina Veterinária e Zootecnia da USP (São Paulo, Brasil). 1: 67.

4 Biddle M.K., Fox L.K., Hancock D.D., Gaskins C.T. \& Evans M.A. 2004. Effects of Storage Time and Thawing Methods on the Recovery of Mycoplasma Species in Milk Samples from Cows with Intramammary Infections. Journal of Dairy Science. 87: 933-936.

5 Chahota R., Katoch R., Majan A. \& Verma S. 2001. Clinical bovine mastitis caused by Geotrichum candidum. Veterinarski ARHIV. 71: 197-201.

6 Chengappa M.M., Maddux R.L., Greer S.C., Pincus D.H. \& Geist L.L. 1984. Isolation and Identification of Yeasts and Yeastlike Organisms from Clinical Veterinary Sources. Journal of Clinical Microbiology. 19: 427-428.

7 Costa E.O, Melville P.A, Ribeiro A.R, Pardo R.B \& White C.R. 1997. Microbiological methods for diagnosis of clinical bovine mastitis. Arquivo Brasileiro de Medicina Veterinária e Zootecnia. 49: 159-167.

8 Crawshaw W.M., MacDonald N.R. \& Duncan G. 2005. Outbreak of Candida rugosa mastitis in a dairy herd after intramammary antibiotic treatment. Veterinary Record. 156: 812-813.

9 Gomes M.I.F.V., Bonassi A. \& Roça R.O. 1997. Características químicas, microbiológicas e sensoriais de leite de cabra congelado. Ciência e Tecnologia de Alimentos. 17: 111-114.

10 Keller B., Scheibl P., Bleckmann E. \& Hoedemaker M. 2000. Differentiation of yeasts in mastitis milk. Mycoses. 1: 17 19.

11 Kuo C.C. \& Chang C.H. 1993. Isolation from mastitis milk of dairy cattle. Journal of the Chinese Society of Veterinary Science. 19: 221-227.

12 Krukowski H., Tietze M., Majewski T. \& Rózanski P. 2000. Survey of yeast mastitis in dairy herds of small-type farms in the Lublin region, Poland. Mycopathologia. 150: 5-7.

13 Lagneau P.E., Lebtahi K. \& Swinne D. 1996. Isolation of yeasts from bovine milk in Belgium. Mycopathologia. 135: 99102.

14 Lavinas F.C., Almeida N.C., Miguel M.A.L., Lopes M.L.M. \& Valente-Mesquita V.L. 2006. Estudo da estabilidade química e microbiológicado suco de caju in natura armazenado em diferentes condições de estocagem. Ciência e Tecnologia de Alimentos. 26: 875-833.

15 Mazur P. 1970. Cryobiology: The freezing of biological systems. Science. 168:939-949.

16 Murdough P.A, Deitz K.E. \& Pankey J.W. 1996. Effects of freezing on the viability of nine pathogens from quarters with subclinical mastitis. Journal of Dairy Science. 79: 334-336.

17 Pelaez C. 1983. Congelación de cuajadas. Alimentaria. 144: 19-22.

18 Pfaller M.A., Burmeister L., Bartlett M.S. \& Rinaldi M. 1998. Multicenter evaluation of four methods of yeast inoculum preparation. Journal of Clinical Microbiology. 26: 1437-1441.

19 Tejada L., Sánchez E., Gómes R., Vioque M. \& Fernández Salgueiro J. 2002. Effect of freezing and frozen storage on chemical and microbiological characteristics in sheep milk cheese. Food Chemistry and Toxicology. 67: 1 .

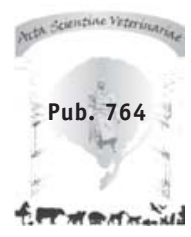

